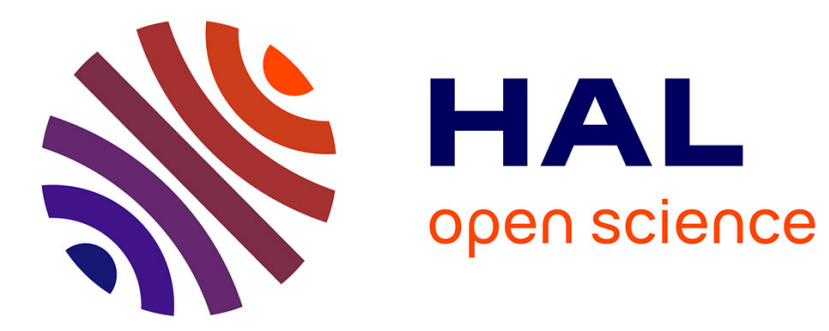

\title{
Asperger's syndrome and high-functioning autism: language, motor and cognitive profiles
}

\author{
Michele Noterdaeme, Elke Wriedt, Christian Höhne
}

\section{To cite this version:}

Michele Noterdaeme, Elke Wriedt, Christian Höhne. Asperger's syndrome and high-functioning autism: language, motor and cognitive profiles. European Child and Adolescent Psychiatry, 2009, 19 (6), pp.475-481. 10.1007/s00787-009-0057-0 . hal-00535173

\section{HAL Id: hal-00535173 \\ https://hal.science/hal-00535173}

Submitted on 11 Nov 2010

HAL is a multi-disciplinary open access archive for the deposit and dissemination of scientific research documents, whether they are published or not. The documents may come from teaching and research institutions in France or abroad, or from public or private research centers.
L'archive ouverte pluridisciplinaire HAL, est destinée au dépôt et à la diffusion de documents scientifiques de niveau recherche, publiés ou non, émanant des établissements d'enseignement et de recherche français ou étrangers, des laboratoires publics ou privés. 


\title{
Asperger's syndrome and high-functioning autism: language, motor and cognitive profiles
}

\author{
Michele Noterdaeme $\cdot$ Elke Wriedt • \\ Christian Höhne
}

Received: 23 February 2009/Accepted: 2 September 2009/Published online: 8 October 2009

(C) Springer-Verlag 2009

\begin{abstract}
The objective of this study is to compare the cognitive profile, the motor and language functioning and the psychosocial adaptation of children with Asperger syndrome (AS) and with high-functioning autism (HFA). Subjects were recruited through the department Autism and Developmental Disorders of the Heckscher-Klinikum. To be included in the study, the full-scale-IQ had to be at least 80. Subjects with AS had to have a normal early language development and subjects with HFA a clear delay in language development, as reported by their parents. The sample consisted of 57 children with Asperger syndrome and 55 children with high-functioning autism. The mean age of the children was 10 years. All subjects were examined with a standardised test battery. Children with AS had a higher full-scale-IQ than children with HFA. This was due to a higher verbal-IQ. There were no significant differences in the performance-IQ. At a mean age of 10 years, subjects with AS had better language skills than subjects with HFA, but at least 30\% showed clear receptive language problems. Motor problems were present in about $50 \%$ of the children with AS and HFA. The level of psychosocial adaptation was clearly reduced, but was comparable for the two groups. The differences in verbal-IQ and language skills between the two groups could be explained through the definition of the syndromes. The presence of language problems in the
\end{abstract}

\section{Noterdaeme $(\square)$}

Klinik für Kinder- und Jugendpsychiatrie und Psychotherapie,

Kapellenstrasse 30, 86154 Augsburg, Germany

e-mail: noterdaeme.michele@josefinum.de;

michele.noterdaeme@1rz.uni-muenchen.de

\section{E. Wriedt · C. Höhne}

Heckscher Klinikum für Kinder- und Jugendpsychiatrie, Psychosomatik und Psychotherapie, Deisenhofener Strasse 28, 81539 Munich, Germany subjects with AS at age 10, the comparable degree of motor impairment and level of psychosocial adaptation question the validity of the distinction between AS and HFA within the category of pervasive developmental disorders.

Keywords Asperger syndrome · High-functioning autism - Intelligence $\cdot$ Language impairment .

Motor disorder

\section{Introduction}

There is a discussion about the nosological validity of the different subtypes within the category of the pervasive developmental disorders. Both Asperger's syndrome (AS) and high-functioning autism (HFA) are characterised through the presence of qualitative impairment in social interaction and non-verbal communication as well as the occurrence of stereotyped, repetitive behaviours. According to the ICD-10 criteria, AS additionally requires an age appropriate language development and a normal intelligence [35]. The concept of HFA refers to a form of autism without mental retardation, but with a clear delay or impairment of language acquisition at an early stage in development. It is still unclear if these two syndromes represent different disorders or are variants of one condition.

The criteria for AS have been modified by different authors. Asperger described impairment of social interaction, repetitive behaviour, malfunction of non-verbal communication, motor clumsiness, problems in receptive language function and in communicative language, as well as excessive isolated interests as core features of the disorder [1]. He noted an early onset of language acquisition and at least average intelligence. Wing postulated the possibility of a delayed onset of language acquisition and a mild 
mental retardation in AS [33, 34]. Tantam defined a good command of language, abnormal non-verbal expression and social isolation despite the wish of social contact as main criteria [30]. Unlike Asperger's description, he did not take early language development and cognitive functioning fully into account. Gillberg et al. postulated criteria close to Asperger's original contribution. The authors focussed on the importance of a self-centred attitude, isolated interests and motor clumsiness. They also described a mild mental retardation and a delayed onset of language acquisition [4, 8]. Klin et al. [12] defined isolated interests, early language acquisition as well as unusual sensory interests as core features of the syndrome. The ICD-10 does not include a differentiated description of language functioning. No clinically evident language delay is allowed and the cognitive development within the first 3 years of life has to be normal. Motor clumsiness and isolated interests are described but not obligatory criteria [35].

Cognitive profiles have repeatedly been analysed in subjects with AS and subjects with HFA. High verbal intelligence with better results on the verbal scale than on the performance scale of the Wechsler intelligence test as well as an earlier language development is more likely to be found in persons with AS than in persons with HFA, but the results are far from consistent [6, 7, 13, 23, 24, 27, 29]. Szatmari et al. compared subjects with AS and HFA with a control group of socially impaired children without autism. The results showed that the subjects with AS and HFA differed little on verbal-IQ, performance-IQ or full-scale-IQ. Both groups showed clear deficits in motor coordination, language comprehension, and facial recognition compared to the control group. The differences between the two groups of children with a pervasive developmental disorder were relatively small, and probably reflected a different degree of severity rather than a separate aetiology [29]. Ozonoff et al. analysed the neuropsychological profile of 10 subjects with AS and 13 subjects with HFA. The subjects in the AS group showed a higher verbal-IQ than the subjects in the HFA group. The HFA group had additional deficits in theory of mind and verbal memory. The authors stated that both groups were empirically distinguishable independent of diagnostic criteria [24]. In a more recent study, using a strict definition of AS based on DSM-IV criteria, the same authors compared 23 children with HFA with 12 children with AS with respect to cognitive functioning, current symptoms and early history. The subjects with AS had a higher verbal-IQ than the subjects with HFA, the most significant difference being a high score on the comprehension subtest of the WISC for the AS group. Altogether, the differences between the groups were small [23]. Ghaziuddin compared 22 subjects with AS with 12 subjects with HFA. The subjects in the AS group had a higher full-scale-IQ and verbal-IQ than the subjects in the HFA group. There was no significant difference in
performance-IQ. However, each group included subjects that scored the way the other group did. When the subtest scores were compared, differences emerged only on the subtests "information", "vocabulary" and "arithmetic", scores being higher for the AS group [6]. Saulnier and Klin [27] studied similar groups and found higher verbal-IQ scores and less symptomatology in individuals with AS than in individuals with HFA, but comparable impairments on the Vineland scores, highlighting the adaptive deficits in the two groups. Studies using executive function paradigms to explore differences between AS and HFA produced contradictory results: Rinehart et al. [26] demonstrated deficits in shifting attention only in the HFA group, Kenworthy et al. [11] did not find consistent differences between the groups.

Asperger syndrome is defined by a lack of early language delay. However, few groups have examined differences in these groups beyond early childhood and adolescence. In a retrospective study, Eisenmajer et al. (1998) compared subjects with HFA and AS with respect to autistic symptoms and developmental history. The authors found that early language delay predicts the extent of autistic psychopathology, motor delay and receptive language skills when the children were young, but not at an older age. When the children approached puberty, the difference in the language level between the groups lessened [2]. Howlin's study with high-functioning adults produced similar results: for individuals with HFA or AS older than 18 years, the scores on tests of language comprehension and expression were comparable [10]. Both authors, therefore, questioned the validity of the language criterion as a distinctive marker between groups.

Motor clumsiness has repeatedly been used in the delineation of AS. Manjiviona and Prior [17] compared the level of motor impairment in AS and HFA. Using a standardised test, they found that $50 \%$ of subjects with AS and $66.7 \%$ of the subjects with HFA showed motor problems. The two groups did not differ on either total or subscale impairment scores. They concluded that clumsiness is not a feature to differentiate these disorders.

Longitudinal outcome studies that focussed exclusively on persons with autism and IQs in the normal range indicated that, although the majority of the subjects improved over time, difficulties in terms of communications skills, social adjustment and independent living continued into adulthood. Therefore, there seemed to be little difference in the long-term outcome of the groups $[7,10,16]$.

Although there seems to be clear evidence that AS and HFA are one disorder on the continuum of the autistic spectrum, recent research showed that distinct pattern of grey matter abnormalities and white matter distribution could be detected for the groups, providing some evidence that the underlying neurobiology of AS and HFA is at least partly discrete $[18,19]$. 
The purpose of the present study was to compare the cognitive profile, language and motor performance as well as the psychosocial functioning of children with AS and children with HFA. We used a standardised battery of tests to evaluate the differences between the two groups.

\section{Methods}

Subjects

57 subjects with AS and 55 subjects with HFA participated in the study. The subjects were recruited through the department for children with developmental disorders at the Heckscher-Klinikum over a period of several years (2000 to 2008). The assignment to the diagnostic group "AS" or "HFA" was made using all the available information on each child (standardised tests, clinical information/observation outside the structured ADOS setting, anamnestic data provided by other caretakers than the parents). Parent interviews (ADI-R) [14] and standardised observation (ADOS) [15] were conducted with all participants. Inter-rater reliability data on the ADOS [22] and diagnostic accuracy of the ADOS and ADI-R [21] have been reported previously. Diagnoses were based on ICD-10 criteria. Subjects were included in the HFA group if they met the following ICD-10 criteria: A-criterion: language development was described as impaired by the parents (ADI-R item 9: no single words by age two; ADI-R item 10: no communicative phrases by age three); B-criterion: at least six symptoms out of a list of 12 , with the required distribution (at least two symptoms in the social domain, one in the communication domain, one in the restricted and repetitive behaviour domain); C-criterion: clinical picture not attributable to other pervasive developmental disorders or other conditions. All but two subjects were positive on ADI-R, all subjects were positive on the ADOS.

Subjects were included in the AS group if they met the ICD-10 criteria of AS: A-criterion: early language development had to normal as reported by the parents (ADI-R items 9: single words by age two; ADI-R items 10: communicative phrases by age three); B/C-criterion: social impairment and presence of repetitive and restricted patterns of behaviour were defined as in autism; D-criterion: the diagnosis of autism took precedence over the diagnosis AS. All subjects but one were positive on the ADI-R, all were positive on the ADOS. Misclassifications on the ADI$\mathrm{R}$ were due to minimalisation of the children's problems by the parents.

Excluded from the study were children born before 38 weeks of gestation, children with a history of cerebral palsy, epilepsy or any other kind of diagnosed major neurological condition, bilingually raised children as well as
Table 1 Characteristics of the sample

\begin{tabular}{lll}
\hline & $\begin{array}{l}\text { Subjects } \\
\text { with AS } \\
(N=57)\end{array}$ & $\begin{array}{l}\text { Subjects } \\
\text { with HFA } \\
(N=55)\end{array}$ \\
\hline Mean age (years;months) & $11 ; 2 \pm 3 ; 1$ & $10 ; 6 \pm 3 ; 3$ \\
Range & {$[6 ; 8-19 ; 9]$} & {$[6 ; 1-19 ; 5]$} \\
Sex (female:male) & $5: 52$ & $6: 49$ \\
Class (lower:middle:upper) & $3: 34: 20$ & $7: 37: 11$ \\
Siblings (none:1:>1) & $23: 28: 6$ & $18: 26: 11$ \\
Handicapped siblings & 2 & 3 \\
Living situation (parents:institution) & $52: 5$ & $51: 4$ \\
\hline
\end{tabular}

children with a history of hearing or sight problems. The groups were matched for age and sex and had to have a full-scale-IQ of at least 80 to be included in the study. Children received a standardised battery of language, cognition and neurological/motor tests. Table 1 describes the sample.

Procedure

\section{Cognitive profile}

Depending on age, IQ was measured with the "HamburgerWechsler-Intelligenztest für Kinder-III" (HAWIK-III) [31] or the "Hamburger-Wechsler-Intelligenztest für Erwachsene-Revision" (HAWIE-R) [32]. The analysis of the cognitive profile included only the subjects with a complete version of the WISC (AS: $N=55$; HFA: $N=51$ ).

\section{Language tests}

All participants were assessed by experienced speech therapists. Depending on the age, different tests were used. For the younger children, the "Marburger Sprachverständnistest für Kinder" (MVSK, Elber \& Lohaus 2000) [3], the "Heidelberger Sprachentwicklungstest" (HSET, Grimm und Schöler) [9] or the "Test zur Überprüfung des Grammatikverständnisses" (TROG-D, Fox 2007) [5] were used, for older children the "Allgemeine deutscher Sprachtest" (ADST, Steinert 1978) [28]. Spontaneous speech/conversation samples were recorded for all children. The children were rated on five categories. "Expressive language" (vocabulary and grammar) and "receptive language" (word and sentence comprehension) were rated on a three-point scale $(0=$ age appropriate; $1=$ moderately delayed $/$ deviant; 2 = clearly delayed/deviant) using test scores, clinical observations outside the test situation, anamnestic data on language functioning. "Echolalia" (immediate, delayed, stereotyped phrases; ADI-R-item 33, ADOS-item A3), "pronominal reversal" (ADI-R-item 37, ADOS-item A4) and "intonation" (peculiar intonation, volume, rhythm, 
speech rate; ADI-R-item 40, ADOS-item A2) were rated on a two-point scale using parent information (presence of the behaviours at age 4-5) and direct observation during the evaluation sessions of the children. If the target behaviour could not be observed during the ADOS sessions, the parent rating was used.

\section{Motor functioning}

All subjects received a standard neurological evaluation and were assessed on five motor domains (fine motor skills, gross motor skills, coordination, balance and oral motor skills) according to the procedure described in Noterdaeme et al. [23]. If children were scored as impaired on at least three domains, motor functioning was rated as "clearly deviant".

\section{Psychosocial functioning}

The level of psychosocial functioning was assessed using the following: school level main stream school/basic level (comprising a maximum of nine school years), main stream school-higher level (comprising a maximum of 13 school years), special education classes (with reduced academic load); medication ("yes" or "no" over the assessed life span); speech therapy ("yes" or "no" over the assessed life span); global level of psychosocial functioning (Axis 6 of the multiaxial classification scheme) [25]. We grouped the levels of functioning of Axis 6 into three categories: $1=$ normal/lightly impaired; $2=$ moderately impaired; $3=$ severely impaired. The assessed domains for the category global psychosocial functioning were: social functions (interaction within and outside the family, contact with peers and adults), independency (age appropriate daily life skills at home and outside) and school/academic achievement (in accordance with the intellectual level of the subject). A score " 1 " was given, when the child performed appropriately or with relatively little support on at least two of the three domains; the score " 2 " meant a moderately impaired performance on at least two of the three domains; the score " 3 " was given when the subject needed extensive support on all three domains (e.g. no friends or contact, aggressive behaviour in social context, not making homework or being able to go to school alone, needing individual coaching to be able to stay in the classroom).

\section{Statistical analysis}

An analysis of variance was used to assess differences in the cognitive profiles of the two groups. Differences in language, motor functioning and psychosocial functioning were calculated with the Chi-square test.

\section{Results}

Cognitive profile

The mean scores obtained by the subjects with HFA and AS on the IQ profiles are shown in Table 2. Subjects with AS had a higher mean full-scale-IQ and a higher mean verbal-IQ than the subjects with HFA. The difference between the groups on the performance-IQ was not significant. Subjects with AS performed better on all subtests of the verbal-IQ than subjects with HFA. The only subtest within the performance-IQ which reached an appropriate
Table 2 Cognitive profiles

Numbers within brackets are standard deviations

** Significant at $p<0.01$

*** Significant at $p<0.001$

\begin{tabular}{lccc}
\hline & Subjects with & Subjects with & $F(p)$ \\
& AS $(N=55)$ & & \\
\hline Scores on the WISC & & & \\
Full scale IQ (SD) & $104.1( \pm 14.3)$ & $94.0( \pm 9.6)$ & $15.8(0.001)^{* * *}$ \\
Verbal IQ & $113.3( \pm 18.5)$ & $97.6( \pm 12.4)$ & $26.1(0.001)^{* * *}$ \\
Information & $12.6( \pm 3.3)$ & $10.7( \pm 2.5)$ & $11.4(0.001)^{* * *}$ \\
Similarities & $12.6( \pm 2.9)$ & $9.8( \pm 1.8)$ & $34.9(0.001)^{* * *}$ \\
Arithmetic & $11.4( \pm 3.8)$ & $9.7( \pm 3.4)$ & $5.9(0.016)^{* *}$ \\
Vocabulary & $12.5( \pm 3.3)$ & $9.4( \pm 2.4)$ & $29.7(0.001)^{* * *}$ \\
Comprehension & $9.6( \pm 3.4)$ & $7.3( \pm 2.4)$ & $15.8(0.001)^{* * *}$ \\
Performance IQ & $96.5( \pm 16.2)$ & $92.8( \pm 11.6)$ & $2.5(0.1)$ \\
Picture completion & $9.9( \pm 2.6)$ & $9.7( \pm 2.2)$ & $0.29(0.6)$ \\
Picture arrangement & $8.6( \pm 3.0)$ & $6.6( \pm 2.2)$ & $14.5(0.001)^{* * *}$ \\
Block design & $11.9( \pm 1.9)$ & $9.9( \pm 2.6)$ & $3.5(0.06)$ \\
Coding & $8.1( \pm 2.8)$ & $7.5( \pm 2.2)$ & $1.5(0.22)$ \\
Object assembly & $8.9( \pm 3.3)$ & $8.8( \pm 2.8)$ & $0.01(0.9)$ \\
\hline
\end{tabular}


Table 3 Language functioning

\begin{tabular}{lccc}
\hline & $\begin{array}{c}\text { Subjects } \\
\text { with AS } \\
N=57\end{array}$ & $\begin{array}{l}\text { Subjects } \\
\text { with HFA } \\
N=55\end{array}$ & Chi-square $(p)$ \\
\hline Number of children & & & \\
Expressive language & & & $24.7(0.001)$ \\
$\quad$ Normal & 38 & 16 & \\
Moderately delayed & 17 & 25 & \\
Clearly delayed/deviant & 2 & 14 & \\
Receptive language & & & \\
Normal & 35 & 13 & \\
Moderately delayed & 13 & 30 & \\
Clearly delayed/deviant & 9 & 12 & \\
Pronominal reversal & & & \\
Not observed/reported & 43 & 8 & \\
Present/reported & 14 & $47.001)$ \\
Echolalia & & & \\
Not observed/reported & 33 & 2 & $0.504(0.7)$ \\
Present/reported & 24 & 53 & \\
Intonation abnormalities & & & \\
Not observed & 3 & 4 & \\
Present & 54 & 51 & \\
\hline
\end{tabular}

significance level was the picture arrangement test with better results for the AS group.

\section{Language and motor functioning}

The HFA group showed statistically significant more deficits in expressive language and receptive language functioning. About $30 \%$ of the subjects in the AS group had a clear impairment in receptive language skills at the time of the study, even if parents rated early language development as normal or above average. In the HFA group, $23 \%$ of the children had expressive and receptive language skills within the normal range (Table 3).

Echolalia and pronominal reversal were more frequent in subjects with HFA. There was no significant difference between the groups for the category "intonation".

Motor problems were identified in 53\% of children with AS and $47 \%$ of children with HFA.

\section{Psychosocial functioning}

The majority of the subjects in the sample were schoolaged children at the time of the study. A small proportion of the subjects had finished school and was enroled either in university/college ( $N=3$, Asperger; $N=2$, HFA) or in special job-preparing programs (Table 4).

Most of children were enroled in mainstream schools, often with additional individual support in the classroom. A larger number of subjects from the HFA group were enroled in special schools (reduced number of children in the classroom, reduced academic load). 40 subjects with AS $(70 \%)$ and 41 subjects with HFA (74\%) were at least moderately to severely impaired with respect to psychosocial functioning. The proportion of children needing medication was about the same in both groups. The most frequently prescribed medication was methylphenidate for hyperactive and inattentive behaviour, followed by neuroleptic medication for aggressive behaviour and sleep problems. A few children with AS had speech/language therapy in their preschool years, mostly for phonological problems and only for a short period of time, whereas a high percentage of children with HFA had speech/language therapy over several years.
Table 4 Level of psychosocial functioning

\begin{tabular}{|c|c|c|c|}
\hline & $\begin{array}{l}\text { Subjects } \\
\text { with AS } \\
N=57\end{array}$ & $\begin{array}{l}\text { Subjects } \\
\text { with HFA } \\
N=55\end{array}$ & Chi-square $(p)$ \\
\hline \multicolumn{4}{|l|}{ Number of children } \\
\hline Global level of psychosocial functioning (ICD-10) & & & $1.54(0.905)$ \\
\hline Minimal/light impairment & 17 & 14 & $2.6(0.75)$ \\
\hline Moderate impairment & 31 & 34 & \\
\hline Severe impairment & 9 & 7 & \\
\hline School level & & & $23.28(0.001)$ \\
\hline \multicolumn{4}{|l|}{ Mainstream school } \\
\hline Basic level (max. nine school years) & 22 & 26 & \\
\hline Higher level (max. 13 school years) & 24 & 9 & \\
\hline Special schools & 11 & 20 & \\
\hline Speech therapy & 2 & 49 & $82.6(0.000)$ \\
\hline Medication & 20 & 13 & $0.216(0.1)$ \\
\hline
\end{tabular}




\section{Discussion}

The purpose of this study was to evaluate and compare the cognitive profile, the language and motor performance as well as the level of psychosocial integration in two samples of children with pervasive developmental disorders, using a standardised battery of tests and extensive clinical data. The subjects were matched for sex and age, the mean age of this sample being 10 years. The particular strength of our work is that it involves a large, well-studied group of children which were carefully assigned to the AS or HFA group using strict ICD-10 criteria, including the precedence rule. The main difference between AS and HFA was the presence of an early language delay, as reported by the parents.

The analysis of the cognitive profiles showed that the subjects with AS had significantly higher scores on the fullscale-IQ and the verbal-IQ than the subjects with HFA. The difference on the performance-IQ was not significant. As found in many previous studies, both groups scored lowest on Comprehension and Picture arrangement, and highest on Block Design in the performance scale, suggesting a specific intellectual structure with strengths in visuospatial abilities and deficits in social intelligence. The extent of the differences varied between the studies and could be explained by sample size, mean age of the groups, as well as the definition of the syndromes [6-8, 13, 19, 20].

The language data showed that subjects with HFA had clearly more expressive and receptive language problems than the subjects with AS. This result could be interpreted as a direct consequence of the definition criteria of the study sample. Yet, more than $30 \%$ of the subjects with AS also had language problems, especially in the receptive domain. These results might seem unexpected, as a normal early language development was one of the inclusion criteria for the subjects with AS.

The ICD-10 criteria required the presence of single words at age 2 and communicative phrases at age 3 . The inclusion criterion for the sample was based on retrospective parent information about the early language development of their child. Using this criterion probably allowed for a reliable classification as clearly delayed (no functional language at age 2 being a "red flag" for most parents and paediatricians) as was the case in the HFA group, whereas more subtle problems in early language development (as was probably true for the AS group) especially in comprehension skills might not be noticed by the caretakers of the child or might only be apparent at the age when higher language skills are expected to be present (understanding double meaning, irony, metaphor, etc.).

The results showed that a high percentage of the children with HFA had speech therapy for an extended period of time. Looking at data on early language development through reports of speech therapists indicated that these children showed a clear improvement of their language skills over time. Comparing actual data to previous language data proved to be difficult for the AS group, as most children did not have any kind of prior language assessment. So even if at the time of the study and a mean age of 10 years, the language performance of children with AS was still better than the performance of the children with HFA, the differences might not be as clear as at earlier stages in development. Eisenmajer et al. and Howlin [2, 10] found that early language delay did not necessarily predict language outcome in adolescence or adulthood. It has been reported that young children diagnosed with HFA may shift to a rather "Asperger-like" symptomatology in later life, especially when they develop fluent language skills [7, 10, 16]. Consequently, language problems might rather reflect a general developmental delay than a core feature of the syndrome.

Summarising our findings showed that both groups of children differed significantly on the verbal scale of the intelligence test and on measures receptive and expressive language skills. These differences were mainly due to the selection and definition criteria of the group. There were no significant differences in non-verbal cognitive performance, in motor performance and in the level of psychosocial adaptation. These results add to the evidence that HFA and Asperger can be considered as one group on a continuum of autism spectrum disorders.

\section{References}

1. Asperger H (1944) Die autistischen Psychopathien im Kindesalter. Archiv Psychiatr Nervenkr 117:76-136

2. Eisenmajer R, Prior M, Leekam S, Wing L, Ong B, Gould J, Welham M (1998) Delayed language onset as a predictor of clinical symptoms in pervasive developmental disorders. J Autism Dev Dis 28:527-533

3. Elben C, Lohaus A (2000) Marburger Sprachverständnistest für Kinder (MSVK). Hogrefe, Bern

4. Ehlers S, Gillberg C (1993) The epidemiology of Asperger syndrome: a total population study. J Child Psychol Psychiatry 34:1327-1350

5. Fox A (2007) Test zur Überprüfung des Grammatikverständnisses (TROG-D). Schulz-Kirchner, Idstein

6. Ghaziuddin M, Mountain-Kimchi K (2004) Defining the intellectual profile of Asperger syndrome: comparison with highfunctioning autism. J Autism Dev Dis 34:279-284

7. Gilchrist A, Green J, Cox A, Burton D, Rutter M, Le Couteur A (2001) Development and current functioning in adolescents with Asperger syndrome: a comparative study. J Child Psychol Psychiatry $42: 227-240$

8. Gillberg I, Gillberg C (1989) Asperger syndrome: some epidemiological considerations-a research note. J Child Psychol Psychiatry $30: 631-638$

9. Grimm H, Schöler H (1978) Heidelberger Sprachentwicklungstest (HSET). Hogrefe, Göttingen 
10. Howlin P (2003) Outcome in high functioning adults with autism with and without early language delays: Implications for the differentiation between autism and Asperger syndrome. J Autism Dev Dis 33:3-13

11. Kenworthy L, Black D, Wallace G, Ahluvalia T, Wagner A, Sirian L (2005) Disorganisation: the forgotten executive dysfunctions in high-functioning autism (HFA) spectrum disorders. Dev Neuropsychol 28:809-827

12. Klin A, Pauls D, Schultz R, Volkmar F (2005) Three diagnostic approaches to Asperger syndrome: implications for research. J Autism Dev Dis 35:221-234

13. Koyama T, Tachimori H, Osada H, Takeda T, Kurita H (2007) Cognitive and symptom profiles in Asperger syndrome and highfunctioning autism. Psychiatry Clin Neurosci 6:99-104

14. Lord C, Rutter M, Le Couteur A (1994) Autism Diagnostic Interview-Revised: a revised version of a diagnostic interview for caregivers of individuals with possible pervasive developmental disorders. J Autism Dev Dis 24:659-685

15. Lord C, Risi S, Lambrecht L, Cook E, Leventhal B, Dilavore P, Pickles A, Rutter M (2000) The Autism Diagnostic Observation Schedule-Generic: a standard measure of social and communication deficits associated with the spectrum of autism. J Autism Dev Dis 30:205-222

16. Mawhood L, Howlin P, Rutter M (2000) Autism and developmental receptive language disorder-a comparative follow-up in early adult life. I: cognitive and language outcomes. J Child Psychol Psychiatry 41:547-559

17. Manjiviona J, Prior M (1995) Comparison of Asperger syndrome and high-functioning autistic children on a test of motor impairment. J Autism Dev Dis 25:23-39

18. McAlonan G, Suckling J, Wong N, Cheung V, Lienenkämpter N, Cheung C, Chua S (2008) Distinct patterns of grey matter abnormality in high-functioning autism and Asperger's syndrome. J Child Psychol Psychiatry 49:1287-1295

19. McAlonan G, Cheung C, Cheung V, Wong N, Suckling J, Chua S (2009) Differential effects on white matter systems in highfunctioning autism and Asperger's syndrome. Psychological Medicine 1-9 (Epub)

20. Noterdaeme M, Mildenberger M, Minow F, Amorosa A (2002) Evaluation of neuromotor deficits in children with autism and children with a specific speech and language disorder. Eur J Child Adolesc Psychiatry 11:219-225
21. Noterdaeme M, Mildenberger M, Sitter S, Amorosa A (2002) Parent information and direct observation in the diagnosis of pervasive and specific developmental disorders. Autism 6:159168

22. Noterdaeme M, Kurz U, Mildenberger M, Sitter S, Amorosa A (1999) Ausschluß rezeptiver Sprachstörungen mittels des ADOS (Autism Diagnostic Observation Schedule). Z Kinder Jugendpsychiatr Psychother 27:251-257

23. Ozonoff S, South M, Miller J (2000) DSM-IV-defined Asperger syndrome: cognitive, behavioral and early history differentiation from high-functioning autism. Autism 4:29-46

24. Ozonoff S, Rogers S, Pennington B (1991) Asperger's syndrome evidence of an empirical distinction from high-functioning autism. J Child Psychol Psychiatry 3:1107-1122

25. Remschmidt H, Schmidt M, Poustka F (2001) Multiaxiales Klassifikationschema für psychsiche Störungen des Kindes- und Jugendalters nach ICD-10. 4. Auflage. Huber, Bern

26. Rinehart N, Bradshaw J, Moss S, Brereton A, Tone B (2001) A deficit in shifting attention present in high-functioning autism but not in Asperger's disorder. Autism 5:67-80

27. Saulnier C, Klin A (2007) Brief report: social and communication abilities and disabilities in higher functioning individuals with autism and Asperger syndrome. J Autism Dev Dis 37:788-793

28. Steinert J (1978) ADST Allgemeiner Deutscher SprachtestADST. Westermann, Braunschweig

29. Szatmari P, Bartolucci G, Bremner R (1989) Asperger's syndrome and autism: comparison of early history and outcome. Dev Med Child Neurol 31:709-720

30. Tantam D (1988) Asperger's syndrome. J Child Psychol Psychiatry 29:245-255

31. Tewes U, Schallberger P, Rossman U (1999) HAWIK-III Hamburg-Wechsler-Intelligenztest für Kinder. Huber, Bern

32. Tewes U (1984) HAWIE-R: Hamburg-Wechsler Intelligenztest für Erwachsene-Revision. Huber, Bern

33. Wing L (1981) Asperger's syndrome: a clinical account. Psychol Med 11:115-129

34. Wing L (2000) Past and future of research on Asperger syndrome. In: Klin A, Volkmar F, Sparrow S (eds) Asperger syndrome. Guildford, New York, pp 418-432

35. World Health Organization (1991) Internationale Klassifikation psychischer Störungen. ICD-10 Kapitel V (f). Dilling H, Monbour W, Schmidt M. Huber, Bern 